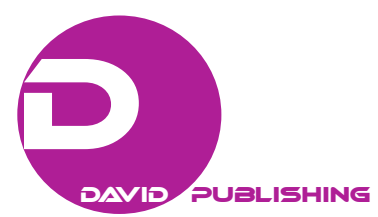

\title{
Investigation on the Quality of Financial Enterprises' XBRL Formatted Financial Report and Its Market Effect
}

\author{
Zhenkun Wang, Yihan Wang \\ Nanjing University of Finance \& Economics, Nanjing, China
}

\begin{abstract}
The application of extensible business reporting language (XBRL) has been widely used across the globe in recent years. Many countries already made XBRL mandatory in their accounting system. The financial industry is normally the first XBRL network report implementer in these countries and it has its own industry classification standard. However, there are many issues been reported on the quality of XBRL formatted financial statement in the financial industry, such as project omission, project misstatements, account omission, and amount misstatements. This paper has conducted an empirical research on the quality of XBRL financial statement in the financial industry based on all samples available from the Shanghai stock exchange and analyzed the market effect of these issues for over six year window period. A web presentation quality evaluation criteria evaluation model was used in the investigation. Evidences indicate that the number of errors in report item omissions was the biggest problem in XBRL formatted financial reports comparing with other types of errors, while this affected the growth rate of company, unexpected rate of return, and the adoption of XBRL. Suggestions on solving these issues are then provided after comparing with the data point methodology (DPM) implementation for XBRL financial reporting in European countries, especially the World Bank.
\end{abstract}

Keywords: financial reporting, XBRL, ISP, data point methodology (DPM), information quality, market effect

\section{Introduction}

Extensible business reporting language (XBRL) is a computer language designed to transfer financial information over the Internet. It is a new technology that can integrate and maximize the usability of financial data. XBRL was promoted by Hoffman in 2006, supported by American Institute of Certified Public Accountants (AICPA). By today, XBRL has been utilized by many stock exchange, accounting firms, and financial service and information providers across the globe. XBRL specification and taxonomy have become the focal point of academic research in recent years.

U.S. Securities and Exchange Commission (SEC) was one of the earliest developer and adopter of XBRL. The SEC issued the first rule of XBRL in February 2005. The motivation for it was to examine the feasibility and desirability of using XBRL-gagged data on a more wide-spread and even mandatory basis for the near future, after XBRL format becomes more commonly utilized. Debreceny, Gray, Ng, Lee, and Yau (2005) have critically examined the implications and feasibility of the rule as part of a working party under the aegis of the

Zhenkun Wang, Ph.D., Nanjing University of Finance \& Economics, Nanjing, China.

Yihan Wang, M.Sc., Nanjing University of Finance \& Economics, Nanjing, China.

Correspondence concerning this article should be addressed to Zhenkun Wang, Department of Accounting, Nanjing University of Finance \& Economics, 3rd Wenyuan Road, Nanjing, Jiangsu 210023, China. 
Information Systems and Artificial Intelligence/Emerging Technologies section of the American Accounting Association. They found very positive evidence to support the SEC's initiative for the purposes of furthering greater transparency, stewardship, and the smooth functioning of capital markets. The committee takes XBRL as vital for the democratization of markets and recommends that the SEC not only considers adopting XBRL to form 8-K filings but eventually mandates the XBRL format for all submissions made to the SEC, which was realized in July 2009 (Aguilar, 2009). Soon, many other countries, including Canada, Australia, the UK, most European countries, and the South Korean, have actively supported the adoption of XBRL, most of which have made it mandatory for financial report.

China has started promoting the application of XBRL since 2004. Shanghai stock exchange (SSE) has required all listed companies to provide XBRL formatted financial report from 2005, which makes China to be one of the first countries that has mandated the application of XBRL. The Ministry of Finance in China (MFC) has published the general taxonomy in 2010, to become the foundation taxonomy in Chinese XBRL application system. Based on that, in order to satisfy the special needs of different industries, MFC has published extended taxonomy for oil and gas and banking industries.

After over 17 years of exploration, XBRL application projects have achieved initial success around the world. It has become the primary format for the disclosure of accounting information. While XBRL application is reaching the end of the first adoption period, it is important to discuss and conclude the impact of XBRL on the quality of financial report.

\section{Literature Review}

\section{Theoretical Foundation for the Assessment for the Quality of Financial Report}

There are two methods to evaluate the quality of financial report: the Financial Accounting Standards Board (FASB) approach (user's need point of view) and the SEC approach (investor's benefit point of view). U.S. FASB has published the qualitative characteristics of accounting information in 1980, in which it clearly stated that the qualitative characteristics of accounting information include: (1) primary quality of decision making - relevance and reliability, while relevance includes predictive value, feedback value, and timeliness; (2) interactive quality: comparability; (3) users specified quality-understandability; and (4) common restrictions - cost benefit principle and importance. The president of U.S. Securities and Exchange Commission emphasized that credibility and integrity, transparency, fairness, comparability, and full disclosure characteristics are the main requirements on the quality of financial information. Whereas, the Chinese accounting standard-basic principle stated that the requirement for the quality of financial report are: reliability, relevance, comparability, understandability, substance over form, importance, prudence, and timeliness.

Ge and Chen (2001) combined the FASB approach and SEC approach. They suggested that the evaluation of cooperate financial report should include two parts: the quality of content and the quality of statement in financial reporting, which can be separated as relevance, reliability (decision usefulness), and transparency (protect creditors), while transparency can be further embodied as importance, comparability, neutrality, clearance, completeness, full disclosure, and substance over form.

Since the quality of financial report is a context-specific issue, many other researchers also described the quality of financial report using different criteria, such as Dechow and Dichev (2002), Schipper and Vincent (2003), and Daske and Gebhardt (2006). However, different user groups will have different preferences 
towards specify criteria, such as the usefulness and importance. Therefore, measuring the quality of financial reporting seems problematic (Botosan, 2004). Consequently, many other researchers who used indirect methods had found attributes that were believed to influence the quality of financial report, such as financial restatements, earnings management, and timeliness (Cohen, Krishnamorthy, \& Wright, 2004; Barth, Landsman, \& Lang, 2008).

\section{Theoretical Foundation for the Assessment for the Quality of XBRL Formatted Financial Report}

Evaluating XBRL formatted financial report is different from traditional financial report, because many criteria mentioned above become as a matter of face issue, such as timeliness and accessibility. Despite the progress made in reducing extension elements, XBRL US has identified other issues causing high error rates (all data below are quoted from Brands, 2013): reporting a negative value for an account that was expected to have a positive value (29\%) and assigning an account element that does not fit in the account's hierarchy, such as an invalid axis member value combination (29\%), for example, a complex fair value disclosure can only include the fair value elements that are related to the disclosure. Other common errors include using an incorrect calculation weight (5\%), missing calculations (3\%), values reported that should be zero or empty (3\%), and values that seem unreasonably large or small (3\%). Therefore, it is important to construct an evaluation system that is specifically designed for XBRL formatted financial report over deference adoption stage.

Nie and Zhou (2011) have suggested using two major evaluation standards, information quality characteristics, and website navigation suitability, to study the web presentation quality of XBRL formatted financial report. They include real-time, completeness, understandability, comparability, and interactivity as major characteristics. In addition, XBRL FR quality should also be assessed by website navigation suitability characteristics, such as the effectiveness of website presentation, the design of auxiliary function the ability of information publicity, and the individuation of information disclosure. Pan and Lin (2012) have tried to construct a three-layer XBRL instance document evaluation system, using general accounting information quality as the first layer; real-time transferability, technical compliance, secure confidentiality, and their sub criteria, as the second layer; and individual relevance and enhanced transparency as the third layer.

Overall, although the development and research of XBRL around the world has been over 10 years, most literature focused on the taxonomy design, but very few on the adoption effect. In this paper, the data collected financial industry will be used to analyze the web presentation quality and market effect of XBRL formatted financial report. An XBRL FR quality evaluation system was also built through the evaluation process.

\section{The Methodology and Model}

\section{Research Objectives}

Listed financial cooperation is the earliest adopter to file XBRL formatted financial report in China, compared to other industries. China Banking Regulatory Commission and the Ministry of Finance have published Extended XBRL Taxonomy Bank for Supervision Report in December 2011. The financial industry has more integrated XBRL financial reporting platform and legal norm than other industries, therefore, it can provide more complete and more scientific data for empirical research. The evaluation of the quality of XBRL formatted financial report of financial industry in China can be considered as a conclusion for XBRL adoption experience over the past 10 years, setting an example for other less XBRL adopted countries, as well as guide the develop of XBRL for the next stage. XBRL formatted financial report of listed banks, securities company, 
insurance companies, and other financial companies in Shanghai stock exchange and Shenzhen stock exchange were selected as the sample data. Eliminating Ningbo Bank and China People's Insurance Group two samples, whose XBRL FR data cannot be obtained, 52 companies were analyzed in the sample pool.

\section{Research Methodology}

Two research methods are employed in this research: (1) descriptive statistics: propose analysis hypothesis, using collected sample company's XBRL formatted financial reports and PDF format financial report, to analyze the web presentation quality of financial reporting; (2) event study method: compare sample stock price fluctuation and abnormal rate of return before and after the event, to examine the impact of price change on information disclosure level before and after the event.

\section{Assumption}

In order to study the quality of XBRL formatted financial report, it should be based on the condition that there is no error in the PDF formatted financial report, to evaluate the resource sharing, information transfer, and other function realization of Internet financial reporting. Therefore, it is assumed that:

(1) The PDF formatted financial reports of cooperates are reliable and complete;

(2) These financial reports are using the same accounting standard;

(3) The information in the PDF formatted financial reports is identified, measured, and reported using transactions or events' economical substance;

(4) The information in the PDF formatted financial reports reflects complete information regarding cooperates' all important transactions or matters relating to the financial position, operating results and cash flow, etc.;

(5) The information in the PDF formatted financial reports is prudence and there is no overvalue or undervalue of assets, liabilities, income, and expenses.

\section{The Construction of Evaluation System}

XBRL is the integration of accounting standard and computer language. Evaluation on the quality of accounting information cannot be separated from the general accounting information quality evaluation standards. The requirements on the quality of accounting information in "the accounting standards for enterprises - basic standards" apply equally in XBRL formatted financial report. Combined with the characteristics of XBRL technology and the realization of the channel, the quality evaluation index has to be expanded. Therefore, the evaluation system was set up with the general accounting information quality standards and specific quality standards. Specific evaluation criteria can be seen in Table 1.

First, among them, "full-transferability" refers to that the enterprise can convert PDF format of financial report information and complete, free from error, which is the precondition for XBRL financial reports to achieve the comparability of data, information, and user decision related functions. Other quality criteria are related to the design of the XBRL service platform. Therefore, the quality of two and only XBRL service platforms in China: Shanghai stock exchange and Shenzhen stock exchange XBRL service platform were firstly evaluated. Then sample companies' 2014 annual report in XBRL formatted to evaluate the "full-transferability" web presentation quality was obtained by marking out the omissions and misstatements in financial report items and amount of money related. Finally, the event study method was used to reveal the market reaction to the disclosure of XBRL report from 2009 to 2014, to verify the influence on the quality of accounting information. 
Table 1

XBRL Internet Financial Reporting Web Presentation Quality Evaluation Criteria

\begin{tabular}{|c|c|c|}
\hline \multicolumn{2}{|c|}{ Quality criteria } & \multirow{2}{*}{$\begin{array}{l}\text { Web presentation description } \\
\text { (1) Integrity: be able to provide a complete XBRL format of financial reporting and financial } \\
\text { information disclosure. }\end{array}$} \\
\hline \multirow{10}{*}{$\begin{array}{l}\text { General } \\
\text { accounting } \\
\text { quality } \\
\text { standards }\end{array}$} & \multirow{2}{*}{ Reliability } & \\
\hline & & $\begin{array}{l}\text { (2) Verifiability: PDF format and XBRL format to provide financial reporting and financial } \\
\text { reporting comparison inspection functions. }\end{array}$ \\
\hline & Relevance & $\begin{array}{l}\text { (1) The financial information provided is related to the information user's decision-making and } \\
\text { can meet the needs of users. }\end{array}$ \\
\hline & Timeliness & (1) Can provide quarterly report, semi-annual report, and annual report in time. \\
\hline & \multirow{2}{*}{ Comparability } & (1) Provides a comparison of the company's major financial data in recent years. \\
\hline & & (2) The function of the comparison of financial data to other companies. \\
\hline & \multirow{2}{*}{ Understandability } & (1) Providing financial ratios, charts, etc. \\
\hline & & (2) Providing financial information to explain the true conversion of a specific quality standard. \\
\hline & \multirow{2}{*}{ Full-transferability } & (1) Include all of the items listed in the PDF format report. \\
\hline & & (2) The amount, accounting subjects, etc., are in full agreement with the PDF financial report. \\
\hline \multirow{3}{*}{$\begin{array}{l}\text { Specific } \\
\text { quality } \\
\text { standards }\end{array}$} & Security & (1) Security has data encryption technology, firewall, and other security control. \\
\hline & \multirow[b]{2}{*}{ Personality related } & (1) A user's query function is provided. \\
\hline & & $\begin{array}{l}\text { (2) Application software is provided, such as intelligent search engine, information } \\
\text { import/export tool, and analysis software. }\end{array}$ \\
\hline
\end{tabular}

\section{The Findings}

\section{Analysis on the Web Presentation Quality of Financial Industry's XBRL Formatted Financial Statements}

Quality analysis for Shanghai stock exchange and Shenzhen stock exchange on the design of information service platform for listed companies. According to the evaluation of the quality index of the XBRL financial reporting standards, excluding full-transferability (truthfully conversion) metrics, the quality evaluation results of Shanghai stock exchange and Shenzhen stock exchange XBRL information service platform are listed in Table 2.

The overall evaluations of XBRL service platform of Shanghai stock exchange and Shenzhen stock exchange are as follows: (1) Service platform cannot guarantee the reliability of the XBRL format of the report and financial information is still what PDF version shall prevail; (2) the two stock exchanges provide the main financial information and the basic query can satisfy user's information demand, but not in the Shenzhen stock exchange query to the statement of changes in equity, information disclosure, and other information; (3) XBRL formatted quarterly report, semi-annual report, and the annual report have advantages to show the dynamic changes of financial data; (4) it is not possible to compare financial data across Shanghai and Shenzhen stock exchange systems and the comparison analysis tool for data within a same stock exchange system is too simple; and (5) there is not secure HTTP channel for the reporting of XBRL formatted financial reports and network hackers can easily tamper financial information.

Financial industry of XBRL financial statement quality analysis. As mentioned earlier, the accuracy of XBRL formatted financial reports in the two major stock exchanges cannot be guaranteed. Chinese financial accounting document ([2014] No. 9) indicates that enterprises should be responsible for the accounting responsibilities for their reported financial reports, and related accounting firm and publicly registered accountants should be responsible for auditing responsibilities. Therefore, in order to obtain an accurate result 
for the accuracy of XBRL formatted financial report, to evaluate the full-transferability criteria, over 400 financial statements, income statements, cash flow statement, and statement of owner's equity of sample companies were collected, filed 2014 in PDF and XBRL format.

Table 2

The Quality of XBRL Information Service Platform for Listed Companies

\begin{tabular}{|c|c|c|c|}
\hline \multicolumn{2}{|c|}{ Quality criteria } & \multirow{2}{*}{$\begin{array}{l}\text { Shanghai stock exchange } \\
\text { (1) Provide information on the financial } \\
\text { statements of the listing corporation, } \\
\text { information disclosure, etc. }\end{array}$} & \multirow{2}{*}{$\begin{array}{l}\text { Shenzhen stock exchange } \\
\text { (1) Provide the financial report of the listing } \\
\text { corporation's balance sheet, profit statement, } \\
\text { cash flow statement, and not set up the } \\
\text { information disclosure column. }\end{array}$} \\
\hline \multirow{8}{*}{$\begin{array}{l}\text { General } \\
\text { accounting } \\
\text { quality } \\
\text { standards }\end{array}$} & \multirow[b]{2}{*}{ Reliability } & & \\
\hline & & $\begin{array}{l}\text { (2) A "PDF" link is provided, but it cannot be } \\
\text { accessed by clicking on the PDF financial } \\
\text { report, and the listing corporation's bulletin } \\
\text { column page can be searched to the PDF } \\
\text { financial report. }\end{array}$ & $\begin{array}{l}\text { (2) In the "financial indicators analysis" } \\
\text { column with "PDF report link", to achieve the } \\
\text { PDF financial report. }\end{array}$ \\
\hline & Relevance & $\begin{array}{l}\text { (1) Provide listed companies showing that the } \\
\text { most important, interpretation, and significant } \\
\text { risk warning, company profile, accounting data } \\
\text { and financial indicators abstract, director } \\
\text { report, changes in the shareholding of the } \\
\text { company, directors, supervisors, senior } \\
\text { managers, and employees, corporate } \\
\text { governance, internal control, financial } \\
\text { reporting, reference documents directory, and } \\
\text { the commercial bank information disclosure, to } \\
\text { meet the needs of different information users. }\end{array}$ & $\begin{array}{l}\text { (1) Provide basic information, capital stock } \\
\text { structure, the main index, balance sheet, profit } \\
\text { statement, and cash flow information; can meet } \\
\text { the basic needs of information users. }\end{array}$ \\
\hline & Timeliness & $\begin{array}{l}\text { (1) Provide } 2008 \text { annual report, since } 2009 \\
\text { quarterly report, semi-annual report, and annual } \\
\text { report. }\end{array}$ & $\begin{array}{l}\text { (1) Provide quarterly report, semi-annual } \\
\text { report, and annual report since } 2009 \text {. }\end{array}$ \\
\hline & & $\begin{array}{l}\text { (1) Provide the comparison of historical data } \\
\text { since } 2009 .\end{array}$ & $\begin{array}{l}\text { (1) Provide the comparison of historical data } \\
\text { since } 2009 .\end{array}$ \\
\hline & Comparability & $\begin{array}{l}\text { (2) Can compare up to three companies of the } \\
\text { same industry, on the company's basic } \\
\text { situation, status of top } 10 \\
\text { unconditional-merchantable shareholders, } \\
\text { balance sheet, income statement, and cash flow } \\
\text { statement. }\end{array}$ & $\begin{array}{l}\text { (2) Can compare up to four companies' balance } \\
\text { sheet, profit statement, and cash flow } \\
\text { statement. }\end{array}$ \\
\hline & \multirow[t]{2}{*}{ Understandability } & $\begin{array}{l}\text { (1) Can compare up to three companies of the } \\
\text { same industry, with the line and bar charts of } \\
\text { their balance sheet, income statement, and cash } \\
\text { flow statement. }\end{array}$ & $\begin{array}{l}\text { (1) Can compare up to four companies of the } \\
\text { same industry, with the line and bar charts of } \\
\text { their balance sheet, income statement, and cash } \\
\text { flow statement. }\end{array}$ \\
\hline & & $\begin{array}{l}\text { (2) Can find the explanations for some of the } \\
\text { financial information. }\end{array}$ & $\begin{array}{l}\text { (2) Explanations for the financial information } \\
\text { cannot be found. }\end{array}$ \\
\hline \multirow{3}{*}{$\begin{array}{l}\text { Specific } \\
\text { quality } \\
\text { standards }\end{array}$} & Security & (1) Can modify data on the http web page. & (1) Can modify data on the http web page. \\
\hline & \multirow{2}{*}{ Personality related } & (1) Instance document cannot be downloaded. & $\begin{array}{l}\text { (1) Provide the download of instance document } \\
\text { of seasonal, semi-annual, and annual financial } \\
\text { report from } 2009 \text {. }\end{array}$ \\
\hline & & $\begin{array}{l}\text { (2) Cannot perform other statistical analysis } \\
\text { than simple comparison of historical data and } \\
\text { same industry. }\end{array}$ & $\begin{array}{l}\text { (2) Cannot perform other statistical analysis } \\
\text { than simple comparison of historical data and } \\
\text { three other companies. }\end{array}$ \\
\hline
\end{tabular}

Analysis by type of industry. The bank reports in XBRL format four types of error occurred, but most mistakes occurred because of omission. The XBRL formatted financial report of joint-stock commercial banks (as shown in Table 3 below) presents the biggest errors, with an average of 13.3 errors; the total error of the local commercial bank's XBRL financial report is 13 , with an average error of 4.25 ; and the average error of 
the state-owned commercial banks is 10.4. The securities industry's XBRL financial report has smaller average number of errors, compared with banks, most of which are omissions in the report projects. The insurance and other industries' XBRL financial reports only have errors in items omission in the sample reports, while other errors, such as project misstatement, amount misstatement, and omission amounts, have not been found yet.

Table 3

Statistics of Errors Found in XBRL FR of Listed Financial Companies

\begin{tabular}{llllll}
\hline Type of companies & $\begin{array}{l}\text { Number of } \\
\text { companies }\end{array}$ & $\begin{array}{l}\text { Number of report } \\
\text { item omissions }\end{array}$ & $\begin{array}{l}\text { Number of errors in } \\
\text { report items }\end{array}$ & $\begin{array}{l}\text { Number of } \\
\text { omissions in the } \\
\text { amount of money } \\
\text { reported }\end{array}$ & $\begin{array}{l}\text { Number of errors in } \\
\text { the amount of } \\
\text { money reported }\end{array}$ \\
\hline Bank & 15 & 128 & 2 & 11 & 4 \\
Security & 21 & 139 & 0 & 16 & 1 \\
Insurance and others & 16 & 29 & 0 & 0 & 0 \\
Total & 52 & 296 & 2 & 27 & 5 \\
\hline
\end{tabular}

Analysis by type of errors. The results show serious problems on reported project item omission, for example, the Industrial and Commercial Bank of China's 2014 annual XBRL format asset liability table fails to report fair value measurement, but the variation is included in the profits and losses of the current period financial assets, account receivable investment, project in construction, financial liabilities, and certificates of deposit which were measured by fair value and their changes are recorded in the profits and losses of the current period; in the PDF formatted cash flow statement of the Bank of Nanjing, it does not reflect the reduction of borrowing funds from other financial institutions.

There is a phenomenon of a small amount of the project error, for example, there is no long-term prepaid expense in the PDF formatted balance sheet of Ping An Bank, but it does exist in the XBRL formatted financial format.

There are big numbers of omissions in the amount of money reported. The Agricultural Bank of China, for instance, has underreported the distribution of shareholders in the integrated owner's equity statement. The cash flow statement of China Merchants Bank in PDF format also did not fill the net increase in borrowing funds and sell repurchasing financial assets net, which is 10,528.

There are only five amount mistakes found in 416 reports, which is small compared to other types of mistakes, such as: The dividend payments at the cash flow statement of the Construction Bank of China is 67,044 in PDF format, but 74,589 in XBRL format; Ping An Bank's trading financial assets at the balance sheet is 10,421 in PDF format, but 13,818 in XBRL format; and the total amount of Country Yuan Securities' cash inflow from operating activities is miscalculated.

Analysis by type of financial report. The total amount of errors in the cash flow statement is the most significant compared to other types of financial statements. Most errors in the statement of cash flows are concentrated in the statement item omissions. Taking XBRL format cash flow statement for example, frequently omitted items are: the net increase of financing lease, the net increase in lending funds and repurchased financial assets, and the net reduction of deposit of the insured and investment.

The errors in balance sheet are relatively concentrated in the financial assets, good will, and project in construction, which were measured by fair value and the change was counted in the profit and loss of current period. Balance sheets in PDF format shown financial assets in the measurement of fair value and the changes 
are recorded in the profits and losses of the current period, whereas, in some of the bank's financial statements in XBRL formatted, it was shown as tradable financial assets and the numbers are inconsistent in different formatted financial statement. The goodwill was not listed in the XBRL formatted balance sheet of the Industrial Bank, Ping An China, or Guoyuan Securities, but existed in the PDF formatted balance sheet. The construction-in-process item, in the PDF formatted balance sheet, was not listed in the XBRL formatted balance sheet of the Shanghai Pudong Development Bank and Industrial and Commercial Bank of China. In addition, many industrial specific items were also omitted.

There is little difference between the XBRL formatted and the PDF formatted income statement, while data in PDF formatted income statements are more detailed, a few items in XBRL formatted financial statement appear as a total number.

The "foreign currency statement translation difference" of the vast majority in the PDF formatted statement of owner's equity is not 0 , but there is no such element in the XBRL formatted report. A small number of banks will report this item in other section under XBRL formatted financial report, while other banks did not process the item at all.

\section{The Market Reaction of XBRL Formatted Report Disclosure in Financial Industry}

Event study method was used to evaluate the reaction of XBRL formatted report disclosure in financial industry. Sixty trading days before the evaluation data is the window period in the model, which is [-60, -2]; the inspection window period is two trading days before and after the disclosure date of annual report, which is [-2, $+2]$. Items below are calculated:

- $R_{i t}=P_{i, t}-P_{i, t-1} / P_{i, t-1}$, rate of return for individual stocks, $P_{i, t}$ means the settlement price of stock $i$ at day $t$

- $R_{m t}=P_{m, t}-P_{m, t-1} / P_{m, t-1}$, market portfolio returns, $P_{m, t}$ means two market index at day $t$;

- $R_{i t}=\alpha_{i}+\beta_{i} R_{m t}+\varepsilon_{i t}$, expect rate of return under CAPM model, $\alpha_{i}$ presents intercept and $\varepsilon_{i t}$ represents regression residual;

- $\mathrm{CAR}_{i}=\sum_{t=t_{1}}^{T} \mathrm{AR}_{i t}$, aggregated abnormal rate of return within window period, while using $\mathrm{A}_{i t}=\mathrm{E} R_{i t}-\left(\alpha_{i}\right.$ $\left.+\beta_{i} R_{i t}\right)$ as the abnormal rate of return, and $t \in\left(t_{1}, T\right)$.

Finally, $\mathrm{CAR}=\alpha+\beta_{1} \mathrm{XBRL}+\beta_{2} \mathrm{GROW}+\beta_{3} \mathrm{UE}+\varepsilon$, while XBRL presents the market reaction level of $\mathrm{XBRL}$ formatted financial information, as a dummy variable with a value of 0 before adopting XBRL, and value of 1 after adopting XBRL. Grow is the growth rate of company, which is main business's increasing rate of income in the model. UE means unexpected earnings, UE $=\mathrm{EPS}_{t}-\mathrm{EPS}_{t-1}$.

The result was calculated from 52 sample companies' sample data from year 2009 to year 2014. Considering the length restriction of this paper, only main findings were listed here. From this research, authors found out that the adoption of XBRL has certainly caused a general level of impact on the abnormal rate of return in the stock market. $T$ test revealed that when the significant level is 0.05 , the linear correlation between XBRL information disclosure and CAR is weak. The $P$ value of double tail probability for $t$ test statistics is much bigger than significant level $\alpha$, therefore it can be concluded that there is no significant difference between the pre and post period of XBRL adoption (see details in Table 4).

However using paired analysis, it has been found out that there is a linear relationship between the paired factors. The $P$ level of XBRL under correlation analysis of factors is 0.074 , which is bigger than the significant 
level, meaning that CAR is affected by the growth rate of company, unexpected rate of return, and the adoption of XBRL, although the impact of XBRL on CAR is not significant.

Table 4

Descriptive Statistics of CAR Before and After XBRL Disclosure

\begin{tabular}{llllll}
\hline & $N$ & Minimum & Maximum & \multicolumn{1}{l}{ Average } & SD \\
\hline 2009, before XBRL disclosure & 42 & -0.0145 & 0.0317 & 0.003265 & 0.0078673 \\
2009, after XBRL disclosure & 42 & -0.0189 & 0.0496 & 0.005217 & 0.0181963 \\
2010, before XBRL disclosure & 47 & -0.0160 & 0.0194 & -0.002495 & 0.0086439 \\
2010, after XBRL disclosure & 47 & -0.0214 & 0.0503 & 0.009203 & 0.0184293 \\
2011, before XBRL disclosure & 51 & -0.0130 & 0.0212 & -0.006751 & 0.0089589 \\
2011, after XBRL disclosure & 51 & -0.0243 & 0.0127 & -0.007683 & 0.0103725 \\
2012, before XBRL disclosure & 52 & -0.0214 & 0.0279 & -0.005471 & 0.0218174 \\
2012, after XBRL disclosure & 52 & -0.0238 & 0.0395 & 0.005743 & 0.0178591 \\
2013, before XBRL disclosure & 52 & -0.0091 & 0.0238 & 0.007297 & 0.0126378 \\
2013, after XBRL disclosure & 52 & -0.0126 & 0.0882 & 0.007815 & 0.0184992 \\
2014, before XBRL disclosure & 52 & -0.0085 & 0.0215 & 0.006173 & 0.0103537 \\
2014, after XBRL disclosure & 52 & -0.0153 & 0.0767 & 0.005324 & 0.0167318 \\
Valid number of samples & 42 & & & & \\
\hline
\end{tabular}

\section{Conclusions}

To conclude, using descriptive statistic and event analysis method to evaluate the web preventative quality of XBRL formatted financial report and its market reaction impact, with the financial institutions from two major stock exchanges in China as sample pool, it has been found out that currently XBRL formatted financial reports in China have considerable number of errors and the market reaction is not significant.

This situation is similar to the early adoption period of the U.S. SEC adoptions. Whereas in Europe, many countries' central bank and bank regulatory authorities are using data point methodology (DPM), with a centralization either on form, data, or data point. However, form-centralized model cannot include information, such as year, scope, currency, and country, and data centralized model cannot be applied directly. The World Bank has already started to promote cooperate social responsibility report using XBRL with taxonomy provided by Global Report Initiative. It has already prepared XBRL formatted financial report and management discussion and analysis file, which pioneered the next stage of XBRL adoption.

The reasons for the insignificant impact of XBRL in current adoption stage are:

(1) XBRL platform function is not yet fully developed and publically available. Although the two stock exchanges in China are mandating listed companies to submit financial reporting in XBRL, the XBRL platform can only perform relatively simple analysis on these data. Many personalization features have not been developed, such as automatic format conversion, data extraction, and on-demand statistical analysis for specific group of financial data.

(2) Many XBRL information sharing platforms stated that the information disclosed in the XBRL instance document is only for reference, while using mainly the PDF version as the final resource. The legal requirement on XBRL formatted financial report is less restricted as the non-XBRL formatted financial reports, some countries even stated that companies and accountants do not need to be responsible for information disclosed in XBRL format. In addition, the current users of the XBRL data are external users. While listed companies have the obligation to report financial report in XBRL, they are not yet able to obtain the benefits of low information 
transfer cost and high efficiency in the preparation of financial report. As a result, current preparers do not really care about the quality of XBRL formatted financial reports, especially on accuracy and completeness.

(3) The taxonomy is the core element of XBRL, it is necessary to define the financial statement elements of relevance, location, and name, while reflecting the accounting standards. The constitution and adoption of XBRL taxonomy has direct effect on the accuracy of financial report items and value. In order to improve the quality of XBRL financial report, many countries have published industry specific XBRL taxonomy and extended taxonomies. China has only started to do so from 2009 (taxonomy for financial institutions) and the end of 2011 (extended taxonomy for banks), same as many other pioneer XBRL adopted countries. As a result, the quality and market impact of XBRL formatted financial report still need to be examined and improved in this early stage of XBRL adoption. As a note for future research, the market reaction of XBRL information can be further studied with annual CAR regression analysis, to test whether the effect of XBRL impact is increasing over the year.

\section{References}

Aguilar, M. K. (2009). The early questions on XBRL adoption. Retrieved from http://www.complianceweek.com/article/4162/the-early-questions-on-xbrl-adoption

Barth, M., Landsman, W., \& Lang, M. (2008). International accounting standards and accounting quality. Journal of Accounting Research, 46(3), 467-498.

Botosan, C. (2004). Discussion of a framework for the analysis of risk communication. The International Journal of Accounting, 39, 289-295.

Brands, K. (2013). Does the SEC XBRL mandate meet investor expectations? Strategic Finance, 95(4), 56-57.

Cohen, J., Krishnamorthy, G., \& Wright, A. (2004). The corporate governance mosaic and financial reporting quality. Journal of Accounting Literature, 23, 87-152.

Daske, H., \& Gebhardt, G. (2006). International financial reporting standards and experts. Perceptions of Disclosure Quality Abacus, 42(3-4), 461-498.

Debreceny, R. S., Gray, G. L., Ng, J. J. J., Lee, K. S. P., \& Yau, W. F. (2005). Embedded audit modules in enterprise' resource planning systems: Implementation and functionality. Journal of Information Systems, 19(2), 7-27.

Dechow, P., \& Dichev, I. (2002). The quality of accruals and earnings: The role of accrual estimation errors. The Accounting Review, 77, 35-59.

Ge, J. S., \& Chen, S. D. (2001). Exploration on the evaluation of the quality of financial report. Accounting Research, 18(11), 9-18.

Hoffman, C. (2006). Financial reporting using XBRL (IFRS and US GAAP edition). New York: Lulu Press, Inc.

Nie, P., \& Zhou, D. (2011). Empirical research based on the web presentation quality of financial report under XBRL environment. Accounting Research, 49(5), 8-14.

Pan, Y., \& Lin, Y. B. (2012). XBRL financial reporting quality evaluation system. Fuzhou University Journal, 53(5), 37-45.

Schipper, K., \& Vincent, L. (2003). Earnings quality. Accounting Horizons, 17, 97-110. 